\title{
App for analysis and development of products with environmental quality
}

XXIV International Conference of the Iberoamerican Society

of Digital Graphics Medellin | Colombia

\author{
Ana Veronica Pazmino \\ UFSC | Brasil | anaverpw@gmail.com
}

\begin{abstract}
The research aims to demystify the term ecological or green products so that they are applied with adequate conceptual bases. Currently, there is a large number of products called sustainable, ecological or green, when in reality they are only recyclable, reusable products, or that use recycled materials. This article presents the theoretical foundation of design guidelines for the environment, and shows the suitability tool for analyzing sustainable products and assisting in the development of products with environmental quality in an application that makes the process of applying guidelines for faster and easier environmental product design for use by designers.
\end{abstract}

Keywords: Design and sustainability; Project guidelines; Environment; Tool.

\section{INTRODUÇÃO}

Com a expansão da problemática ambiental, as iniciativas de prevenção por parte dos governos e o surgimento de consumidores "verdes e conscientes", a indústria está sob uma pressão crescente para desenvolver mudanças nos parâmetros de fabricação tradicional, no volume de produção, na qualidade e na adequação aos novos paradigmas de redução de impactos de resíduos, entre outros.

O Design Sustentável, como processo que busca contemplar os aspectos ambientais em todos os estágios de desenvolvimento de um produto, permitindo reduzir o impacto ambiental durante o seu ciclo de vida, ou seja, reduzindo a geração de resíduos, minimizando o impacto ambiental e economizando custos de descarte, ganha espaço como fator de estímulo de atitudes ecologicamente corretas.

A importância do Design Sustentável está diretamente relacionada com a difusão da necessidade de se buscar alternativas para a finitude dos recursos do planeta, para o desenvolvimento de produtos que permitam compatibilidade com o desenvolvimento humano, qualidade ambiental e qualidade de vida. Dessa forma, no contexto global de preocupação com as questões ambientais, o Design Sustentável vem se destacando como um fator de inovação.

Nesta tendência, alguns fabricantes devido ao aumento da consciência ambiental e a demanda de produtos ecológicos vem desenvolvendo produtos "verdes" que são recicláveis, reciclados e reutilizáveis, projetados para atender um "eco marketing", porém, poucos são sustentáveis ou possuem uma alta qualidade ambiental provocando baixo impacto no ambiente e na sociedade.
(Pazmino, 2017) propôs uma ferramenta que funciona no software Excel e que permite pontuar as características ambientais de um produto, dando um score que determina o grau ambiental. Após dois anos de uso da ferramenta alguns problemas têm sido percebidos: dificuldade de uso e aplicação da ferramenta; falta de praticidade na aplicação da pontuação, necessidade de descrição das diretrizes e maior alcance no meio acadêmico e profissional.

A partir dessas constatações, o problema de pesquisa foi: Como transpor as informações da ferramenta Excel para um sistema que seja prático, informativo e que torne a aplicação das diretrizes de projeto rápida e interativa?

Para resolver o problema da pesquisa, foram estabelecidos os seguintes objetivos. Desenvolver uma interface gráfica e a programação de um aplicativo para smartphone e/ou um site que apoie a análise de produtos e auxilie o projetista na definição de requisitos ambientais nos projetos.

E como objetivos específicos: 1) Apresentar a relevância do design sustentável; 2) Descrever e transpor as diretrizes de projeto da ferramenta em Excel; 3) definir a forma de avaliação e banco de dados; 4) Selecionar produtos para fazer parte do banco de dados; 5) Desenvolver alternativas do aplicativo para subsidiar o processo iterativo de desenvolvimento de sua interface e funcionalidade; 6) Desenvolver as funcionalidades, fluxo de navegação e interação do aplicativo 7) prototipar o aplicativo e testar a usabilidade com grupo focal; 8) registrar o software do sistema. O escopo do artigo é mostrar o sistema na fase de concepção da interface gráfica e o fluxo de informações. Devido a pandemia os objetivos 7 e 8 não foram realizados. 


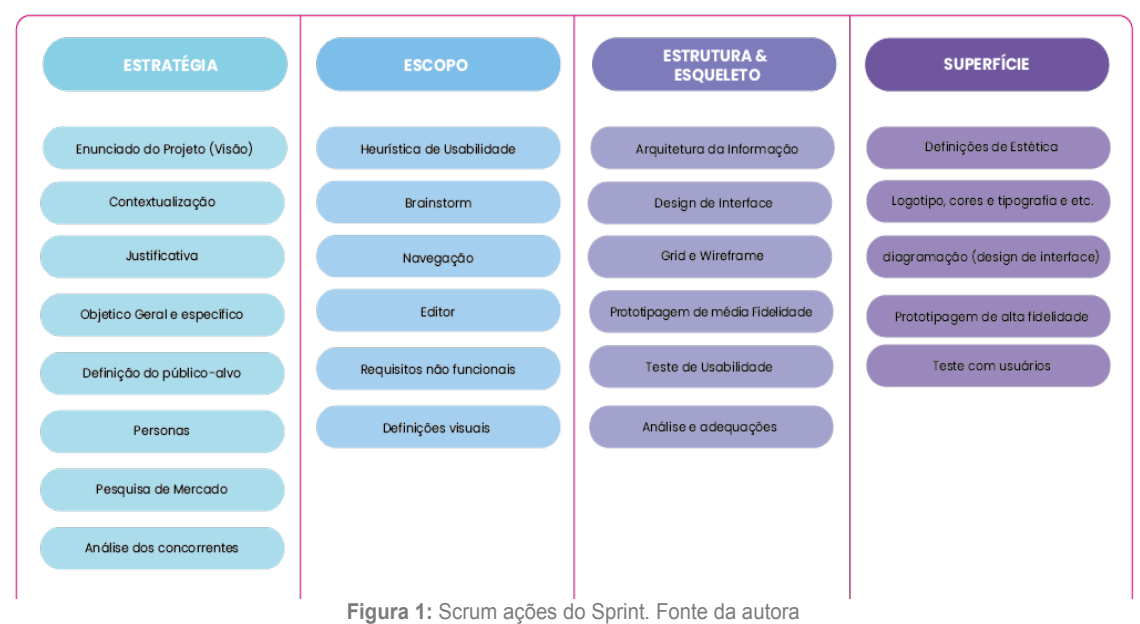

\section{METODOLOGIA}

Para o desenvolvimento do app, foi utilizado um método híbrido como base o método de Jesse James Garret (2010) e métodos ágeis, buscando obter o melhor resultado oriundo desses métodos projetuais. A (Figura 1) mostra o gerenciamento de projeto do SCRUM que detalha todos os métodos de design aplicados. E a (Figura 2) mostra a adaptação do processo de Garrett (2010), com o modelo do Duplo Diamante (2005). Como mostra a (Figura 1) foram as diversas ferramentas e técnicas de projeto utilizadas para auxiliar no desenvolvimento.

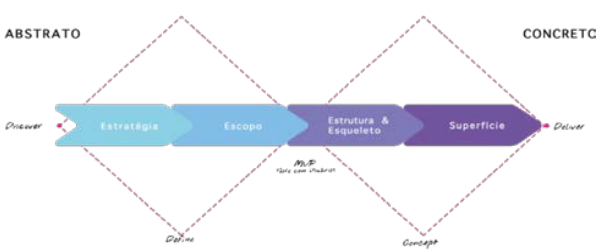

Figura 2: Método duplo diamante e da Garret. Fonte da autora

Schwaber e Sutherland (2013) mencionam que o Scrum é um framework dentro do qual os envolvidos no projeto podem empregar vários processos ou técnicas. Prescreve reuniões de planejamento, revisão e encontros diários. As etapas mostradas na (Figura 1), foram realizadas pelos desenvolvedores.

Além da aplicação de um processo projetual de design a metodologia de pesquisa teve revisão bibliográfica sobre design e sustentabilidade que é a base teórica que sustenta a relevância e conteúdo da ferramenta do app. No item a seguir é mostrada a síntese da pesquisa.

\section{SUSTENTABILIDADE E DESIGN}

O paradigma ambiental está mais difundido na escala global procurando o desenvolvimento sustentável, ou seja, "o atendimento das necessidades do presente sem comprometer a possibilidade de as gerações futuras atenderem as suas próprias necessidades", em um sentido mais amplo significa compatibilidade do crescimento econômico, com desenvolvimento humano e qualidade ambiental.

A crescente preocupação ambiental fez com que o paradigma tradicional mude para provar que uma atividade econômica pode coexistir com a proteção ambiental. Nos últimos anos, aspectos ecológicos se tornaram mais importantes fazendo que as indústrias busquem alternativas para um equilíbrio da economia e a sustentabilidade.

Deve-se lembrar que há algumas décadas atrás a ideia de um mundo finito não foi considerada como limitação, pois se acreditava que não havia limites: o raciocínio de F. W. Taylor (apud Deforge, 1994) consistia em que o infinito da produção seria alimentado pelo infinito dos recursos e puxado pelo infinito do consumo. Hoje se verifica que o alto desenvolvimento tecnológico, o aumento do consumo e a busca pelo alto padrão de conforto criou, em contrapartida, a degradação do meio ambiente, da saúde humana e não diminuiu o índice de pobreza.

O conceito de desenvolvimento sustentável foi abordado pela primeira vez em 1967, na Conferência Intergovernamental pelo Uso Racional e Conservação da Biosfera da Organização das Nações Unidas para Educação, Ciência e Cultura (UNESCO). A sustentabilidade ambiental só foi introduzida no debate internacional mais tarde, por meio do documento da Comissão Mundial pelo Desenvolvimento e Meio Ambiente (WCED), em 1987. Este conceito também serviu de base para a Conferência das Nações Unidas pelo Desenvolvimento e Meio Ambiente (UNCED), a Eco-92, que ocorreu no Rio de Janeiro em 1992, sendo referência fundamental do Quinto Plano de Ação da União Europeia para o Ambiente. As diferentes abordagens, técnicas e ferramentas de design voltadas para a sustentabilidade (ecodesign, green design, design for environment) também tomaram força neste período.

Na década de 70, Papanek (1977) já questionava a profissão de designer da maneira como se apresentava e já exigia uma responsabilidade moral e social por parte 
deste profissional. Argumentava que numa era de produção em massa, o design havia se tornado uma ferramenta poderosa na configuração de produtos e ambientes do homem e ressaltava a importância de se compreender as necessidades básicas dos seres humanos e do meio ambiente.

O autor declarava também que era preciso projetar dentro de um contexto social. Seu papel foi o de cobrar dos designers um maior engajamento e, sobretudo, a criação de um design para atender às necessidades sociais.

Thackara (2008) também aponta o design e suas alternativas para um mundo complexo. O autor destaca que atualmente muitos designers já estão projetando serviços e sistemas visivelmente menos prejudiciais ao ambiente e mais socialmente responsáveis, porém ressalta a necessidade de mudanças, propondo uma mudança de paradigma: 'Nessa nova era de inovação colaborativa, os designers estão tendo de evoluir de autores individuais de objetos, a facilitadores da mudança entre grandes grupos de pessoas' (THACKARA, 2008, p. 21).

Desta forma, observa-se que o design para a sustentabilidade deve ser realizado de maneira colaborativa e deve procurar trabalhar sob os três patamares do desenvolvimento sustentável: ser econômico, não prejudicial ao ambiente e acessível a todos. Como já destacado, muito já tem sido feito sobre este aspecto, mas é preciso considerar que ainda vivemos sob uma economia de política do consumo, num mundo com enormes desigualdades sociais. Com isso, o poder que o design exerce sobre as pessoas pode ser considerado ao mesmo tempo surpreendente e problemático, tornando-o cúmplice deste consumismo acentuado e descarte inadequado.

Sob este aspecto, Batista (2007) defende a tese de que as características dos objetos e soluções desenvolvidas pelo design sofrem imposições socioeconômicas e culturais, uma vez que são indissociáveis das linhas de expansão da economia. Desta forma, seu argumento é o de que existe uma 'racionalidade implícita' nos projetos de design e os objetivos de sua produção não promovem equidade, gerando desigualdade pela dinâmica do mercado, uma vez que apenas os que dispõem de poder aquisitivo podem adquirir um bem, por mais indispensável que seja.

O autor levanta diversas disparidades pautadas à questão da sustentabilidade e sua relação com o design, justificando seu pensamento no fato de que os projetos de design devem possuir uma visão sistêmica que aponte a abrangência, a complexidade e a diversidade de fatores que intervêm na sua realização. Neste sentido é importante considerar que os desenvolvimentos não podem estar limitados por requisitos e parâmetros técnicos, sendo necessário ponderar as diversas dimensões da vida social e do contexto no qual estarão inseridos.

Autores como Deforge e Papanek, defendem uma formação ampla e uma prática profissional comprometida com valores éticos. Não sendo desta maneira, a sustentabilidade desempenhará um papel mistificador, como 'ideologia sem substrato prático'. Batista (2007) ainda ressalta:

Observa-se que a incorporação acrítica dos pressupostos da sustentabilidade no campo do Desenho Industrial, pode instaurar processo de auto-legitimação de produtos eticamente questionáveis e contribui para esmaecer técnica e culturalmente projetos de Desenho Industrial.

A fase de desenvolvimento de projeto é um fator fundamental para a competitividade da indústria, assim o planejamento do produto deve incorporar a questão ambiental simultaneamente ao longo do processo projetual, considerando que produtos ou serviços ecologicamente corretos que não exerçam ou minimizem qualquer impacto ambiental, que sejam passíveis de reciclagem e reutilização são os objetivos da indústria atualmente.

É fato que as preocupações com o desenvolvimento socioeconômico e os impactos gerados devem ser constantes, pois suas consequências comprometem o presente e o futuro da humanidade. Como apontado por Batista (2007), 'o debate sobre a sustentabilidade nos remete a uma visão mais abrangente do mundo em que vivemos e do sistema econômico ao qual estamos submetidos'. Com isso, a abordagem da sustentabilidade deve ser considerada sob um pensamento crítico para resolver as questões relacionadas a prática do design.

O estágio do projeto de um produto estabelece: os componentes que precisam ser extraídos ou criados; a quantidade de energia despendida na fabricação e no uso do produto; a presença ou ausência de substâncias tóxicas; a vida útil do produto; a facilidade ou dificuldade de conserto; sua capacidade de reciclagem; os danos causados ao enterrar ou queimar o produto, caso não seja reciclável, entre outras características.

Segundo McDonough e Braungart (2005) a etapa de projeto é o "primeiro sinal de intenção humana" podendo provocar apenas melhorias, como eliminação de peso e impacto ambiental, ou levar realmente a uma reavaliação dos paradigmas atuais. Para os autores nem a saúde dos sistemas naturais, nem o entendimento da sua complexidade e da inter-relação têm sido consideradas pelo design.

Os autores ainda apontam que muitas vezes a intenção do design consiste apenas em criar um produto atrativo que seja acessível, que cumpra com as regulamentações, que tenha um desempenho aceitável e dure o suficiente para satisfazer às necessidades dos mercados. Porém, ressaltam que embora os produtos satisfaçam aos desejos de fabricantes e consumidores, não estão projetados para beneficiar a saúde humana e ecológica.

O designer projeta atendendo o cliente e ao tomar decisões, parte delas são aquilo que ele conhece e outras são pré-definidas pela empresa, como seu sistema de fabricação. Encontrar soluções ambientalmente adequadas exige pesquisa, conhecimento e auxilio ao longo do projeto para tomar decisões acertadas.

Neste sentido, observa-se que a ferramenta que se propõe aqui é oportuna e aponta para o auxílio no 
desenvolvimento de produtos, serviços e sistemas ambientalmente corretos.

\section{FERRAMENTA DE DIRETRIZES DE PROJETO PARA O MEIO AMBIENTE}

Diversas técnicas, princípios, procedimentos e ferramentas têm surgido para adequar o produto para uma determinada ênfase do projeto, métodos que fazem parte do "design for $x$ " DFX, onde o X representa uma característica do produto maximizada e tratada como objetivo de projeto.

Segundo Pazmino (2017) as diretrizes de design para o meio ambiente são linhas guias que servem para nortear 0 projeto nas fases da geração de alternativas atendendo os critérios ambientais ao longo do ciclo de vidam, de forma que a intenção seja minimizar os impactos ambientais.

Nesta pesquisa foram tratadas as diretrizes que contribuem para a obtenção da qualidade ambiental e redução do impacto do produto, sendo assim, destacamse:

- $\quad$ DFQ (Design for Quality) Projeto para a Qualidade

- DFE (Design for Environment) Projeto para o Meio Ambiente

- $\quad$ DFLC (Design for Life Cycle) Projeto para o Ciclo de Vida

- DFD (Design for Disassembly) Projeto para Desmontagem

- DFR (Design for Reuse and Reciclability) Projeto para Reuso e Reciclagem

O Projeto para a Qualidade (DFQ) trata de um processo sistemático de maximização da qualidade que deve iniciarse no planejamento e desenvolvimento dos produtos e estender-se por todas as operações relacionadas com o ciclo de vida do produto (do berço ao berço).

No Projeto para o Meio ambiente (DFE) busca-se que o planejamento tem que ser orientado ao sistema e não somente ao produto, já que os melhores resultados acontecem quando são considerados todas as operações relacionadas com o ciclo de vida do produto. É importante a relação entre o produto e os sistemas envolvidos em cada fase de vida do produto (extração de matéria prima, fabricação, transporte, manutenção, descarte, reciclagem, descarte no meio ambiente).

O projeto para o ciclo de vida (DFLC) visa buscar soluções para minimizar o impacto ambiental em todas as fases inclusive no pôs uso do produto (descarte) aponta para algumas das principais iniciativas conhecidas e que podem ser consideradas como importantes na promoção da melhoria da qualidade ambiental. Os três 3 R's, reutilização de produtos e componentes, recuperação de materiais e a reciclagem.

O projeto para desmontagem (DFD) objetiva selecionar as estratégias de desmontagem e configurar sistemas de desmontagem manual ou automatizado. A planificação de desmontagem pode ajudar para encontrar melhores estratégias para produtos complexos, com a avaliação quantitativa dos custos de desmontagem e com um ótimo gerenciamento de toda a informação do produto e seu uso anterior. A desmontagem é um problema dos produtos que não são passiveis de desmontagem e são descartados sem permitir 0 aproveitamento de materiais $e$ componentes e tratamento de manufatura.

O objetivo da reciclagem (DFR) é a transformação do produto, ou parte dele, em novas matérias-primas a serem utilizadas para a fabricação do mesmo produto ou de novos produtos. O projeto para reciclagem permite que os produtos que chegaram ao fim da vida útil reentrem no fluxo industrial e sejam incorporados a novos produtos fechando assim o ciclo de vida dos materiais. O produto deve ser otimizado para 0 momento do descarte permitindo ser coletado e devolvido ao uso sob a forma de matérias-primas ou produtos.

O reuso ou reutilização é caracterizado pela retenção da forma do produto ou componente, sempre que possível. Evita a extração de matéria-prima e todo o processo de fabricação. Aqui entra a preocupação no projeto de projetar para facilitar a manutenção e o conserto de forma a estender a vida útil do produto e romper com a cultura de obsolescência planejada.

O (Quadro 1) mostra a ferramenta de diretrizes que foi criada em 2017 para ser usada no programa Excel, com 60 diretrizes, estas foram retiradas de cada abordagem do design for $\mathrm{X}$, organizadas nas diversas fases do ciclo de vida e dotadas de um valor de importância ambiental de 0 a 5. E diretrizes menos relevantes ou importantes com valor entre 0 e 3 .

Os impactos provocados ao meio ambiente acontecem ao longo do ciclo de vida dos produtos e alguns produtos oferecem maior impacto em algumas fases (p.ex.: uma máquina de lavar provoca um impacto durante o uso, embalagens que são descartadas rapidamente no descarte). O conhecimento de ações que reduzam o impacto ambiental do produto favorece para a qualidade ambiental pensando num ciclo fechado do berço ao berço.

No desenvolvimento de um projeto se sugere que as diretrizes sejam consideradas como guias na tomada de decisões do produto que está sendo projetado. A métrica proposta é que se a soma de diretrizes adotadas alcançar 100 pontos ou mais, o produto tem alta qualidade ambiental; com 50 pontos, média adequação à qualidade ambiental; com 25 pontos, baixa qualidade ambiental e abaixo de 25 pontos, o produto não teria nenhuma característica ambiental. Cada diretriz tem diferente grau de importância, por exemplo: Usar Materiais não exauríveis (esgotáveis) tem um grau de importância 5, já visa preservar o material; já a diretriz: Usar Materiais reciclados, tem um grau de importância 3 considerando que um material reciclado, no processo de fabricação provoca impacto ambiental e tem energia incorporada, além de que diversos materiais reciclados não mantem as mesmas características para retornar ao sistema industrial num ciclo fechado.

Cada diretriz de projeto tem uma explicação para o designer, por exemplo: em relação aos polímeros, a ferramenta deve mostrar os símbolos de reciclabilidade que representam a qualidade de reciclagem do material. Por exemplo: polímero PET tem um impacto moderado e o PVC tem um impacto alto como mostra o (Quadro 2). 


\begin{tabular}{|c|c|c|c|}
\hline \multicolumn{4}{|c|}{ Diretrizes de projeto para o meio ambiente } \\
\hline \multicolumn{4}{|c|}{ Aquisição de materias primas } \\
\hline $\mathrm{N}$ & Diretriz & Grau de importância & \\
\hline 1 & $\begin{array}{l}\text { Reduzir a utilização de } \\
\text { materiais e de energia } \\
\text { incorporada }\end{array}$ & & 5 \\
\hline 2 & $\begin{array}{l}\text { Usar Materiais não } \\
\text { exauriveis (esgotáveis) }\end{array}$ & & 5 \\
\hline 3 & $\begin{array}{l}\text { Usar Materiais não } \\
\text { prejudiciais (danosos e } \\
\text { perigosos) }\end{array}$ & & 5 \\
\hline 4 & Usar Materiais reciclados & & 3 \\
\hline 5 & Usar Materiais recicláveis & & 3 \\
\hline 6 & Usar materiais renováveis & & 4 \\
\hline \multicolumn{4}{|c|}{ Fabricação e embalagem } \\
\hline 7 & \begin{tabular}{|l|}
$\begin{array}{l}\text { Favorecer o uso do mono } \\
\text { material }\end{array}$ \\
\end{tabular} & & 3 \\
\hline 8 & $\begin{array}{l}\text { Escolha de técnicas de } \\
\text { produção artesanais }\end{array}$ & & 3 \\
\hline 9 & \begin{tabular}{|l|} 
Menos processos \\
produtivos
\end{tabular} & & 4 \\
\hline 10 & Pouca geração de resíduos & & 5 \\
\hline 11 & $\begin{array}{l}\text { Redução da variabilidade } \\
\text { dos produtos }\end{array}$ & & 3 \\
\hline 12 & \begin{tabular}{|l|}
$\begin{array}{l}\text { Reduzir o consumo de } \\
\text { energia }\end{array}$ \\
\end{tabular} & & 4 \\
\hline 13 & $\begin{array}{l}\text { Utilizar tecnologias } \\
\text { apropriadas e limpas }\end{array}$ & & 5 \\
\hline \multicolumn{4}{|c|}{ Diretrizes de projeto para o meio ambiente } \\
\hline \multicolumn{4}{|c|}{ Distribuição e transporte } \\
\hline 14 & \begin{tabular}{|l|}
$\begin{array}{l}\text { Escolha dos meios mais } \\
\text { eficientes de transporte }\end{array}$ \\
\end{tabular} & & 2 \\
\hline 15 & Logística eficiente & & 2 \\
\hline 16 & Redução de peso & & 2 \\
\hline 17 & Redução de volume & & 2 \\
\hline 18 & Sem embalagem & & 5 \\
\hline 19 & \begin{tabular}{|l} 
Embalagem de material \\
sustentável
\end{tabular} & & 4 \\
\hline 20 & Embalagem monomaterial & & 3 \\
\hline 21 & $\begin{array}{l}\text { Embalagem de material } \\
\text { reciclado }\end{array}$ & & 3 \\
\hline 22 & $\begin{array}{l}\text { Embalagem de material } \\
\text { reciclável }\end{array}$ & & 3 \\
\hline 23 & $\begin{array}{l}\text { Embalagem com material } \\
\text { de baixa energia } \\
\text { incorporada }\end{array}$ & & 3 \\
\hline \multicolumn{4}{|c|}{ Uso/ manutenção e reutilização } \\
\hline 24 & \begin{tabular}{|l|}
$\begin{array}{l}\text { Assegurar a estrutura } \\
\text { modular do produto }\end{array}$ \\
\end{tabular} & & 3 \\
\hline 25 & $\begin{array}{l}\text { Aumentar a confiabilidade } \\
\text { e durabilidade }\end{array}$ & & 5 \\
\hline 26 & Design clássico & & 3 \\
\hline 27 & $\begin{array}{l}\text { Escolher materiais de } \\
\text { consumo limpos }\end{array}$ & & 4 \\
\hline 28 & $\begin{array}{l}\text { Escolher uma fonte de } \\
\text { energia limpa }\end{array}$ & & 3 \\
\hline 29 & \begin{tabular}{|l|} 
Intensificar o cuidado \\
pelo produto
\end{tabular} & & 3 \\
\hline 30 & $\begin{array}{l}\text { Reduzir a quantidade ou } \\
\text { volume de materiais de } \\
\text { consumo requeridos }\end{array}$ & & 3 \\
\hline 31 & $\begin{array}{l}\text { Aumentar o ciclo de vida } \\
\text { do produto e as } \\
\text { possibilidades de } \\
\text { manutenção e reparação }\end{array}$ & & 3 \\
\hline 32 & $\begin{array}{l}\text { Incentivar } 0 \\
\text { compartilhamento }\end{array}$ & & 5 \\
\hline 33 & $\begin{array}{l}\text { Tornar a Manutenção e } \\
\text { reparos mais fáceis }\end{array}$ & & 3 \\
\hline
\end{tabular}

\begin{tabular}{|l|l|}
\hline $\begin{array}{l}\text { Polietileno Tereftalato (PET) } \\
\text { Principal uso: Garrafas de água e refrigerante, fibras para tecidos. } \\
\text { Impacto: MODERADO (indice de reciclagem relativamente alto; } \\
\text { pode conter aditivos tóxicos como tríxido de antimónio). }\end{array}$ \\
\hline $\begin{array}{l}\text { Polietileno de Alta Densidade (HDPE) } \\
\text { Principal uso: Embalagens de leite, suco, xampu, sabào liquido e } \\
\text { oleo de motor. } \\
\text { Impacto: MELHOR (baixa toxicidade, indice de reciclagem } \\
\text { relativamente alto). }\end{array}$ \\
\hline $\begin{array}{l}\text { Policloreto de Vinila (PVC) } \\
\text { Principal uso: Peliculas transparentes, maioria dos filmes plásticos, } \\
\text { embalagem blister. } \\
\text { Impacto: PIOR. }\end{array}$
\end{tabular}

Quadro 2: Materiais e seus índices de reciclabilidade. Fonte: Adaptado de Dougherty, 2011.

O fato de ser material reciclável que nas diretrizes indica uma pontuação de 3 , pode depender do polímero ser abaixado para 2 ou 1 no caso do PVC. E se o produto for um brinquedo infantil que uma criança pode levar a boca, a pontuação deveria ser 0 (zero). O PVC pode ter Ptalatos, conhecidos por causar câncer de fígado em animais (e suspeito de causar desregulação endócrina), juntamente com corantes tóxicos, lubrificantes, antioxidantes e estabilizadores de luz ultravioleta.

Por este motivo, a ferramenta reforça que nem todo polímero reciclável proporciona benefícios ao meio ambiente através da sua reciclagem, pelo contrário, grande parte deles gera impactos muito mais negativos no decorrer do processo. Deve-se lembrar, que muitos materiais não foram desenvolvidos para serem reciclados e que atualmente eles são reciclados devido a quantidade do acúmulo de resíduos encontrados no oceano e em lixões.

A ferramenta de diretrizes, permite que as mesmas sejam utilizadas como um primeiro passo na tomada de decisões do designer ou projetista que deve posteriormente aprofundar suas pesquisas para determinar os melhores requisitos de projeto para que seu produto tenha alta qualidade ambiental. 


\section{RESULTADOS}

Para o desenvolvimento do app foram seguidos os passos das Figuras 1 e 2. A (Figura 3) mostra a tela Home e a (Figura 4) mostra tela de login, do app "Produto Eco de verdade: Guia prático para desenvolver ou analisar produtos com qualidade ambiental"

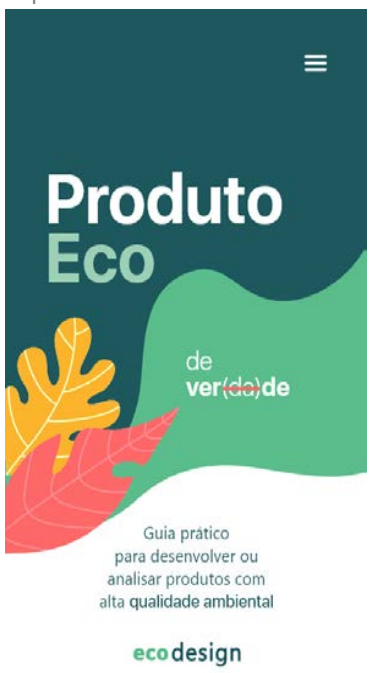

Figura 3: Tela Home do app. Fonte: da autora

Para a elaboração do design das telas foram utilizados o software illustrator e o https://xd.adobe.com/ para simular a usabilidade e permitir os testes com usuários para avaliar a eficiência e eficácia do app durante o desenvolvimento. A (Figura 4) mostra a tela para o usuário fazer um login.

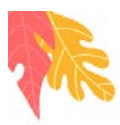

\section{ecodesign}

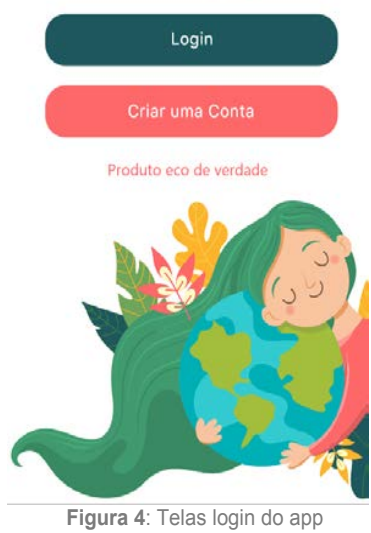

Após ingressar no app o usuário pode selecionar entre as três possibilidades de uso: Consultar as 60 diretrizes da ferramenta; avaliar um projeto ou um produto existente e avaliar seu projeto, nesta tela o usuário deve preencher uma ficha técnica com as características do produto. A (Figura 5) mostra a tela de avaliação e a (Figura 6) as diretrizes.

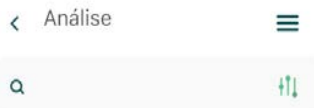

\section{Avalie um Produto}

Avalie e classifique um projeto seu ou produto existente no mercado. Ao final da avaliaçåo, saiba qual o nivel de qualidade ambiental do produto analisado.

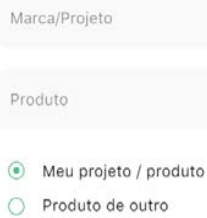

Figura 5: tela de avaliação. Fonte: da autora

\section{Consulte as Diretrizes}

Conheça as diretrizes que podem ser aplicadas ao longo do ciclo de vida de um produto e desenvolva um produto verde de verdade.

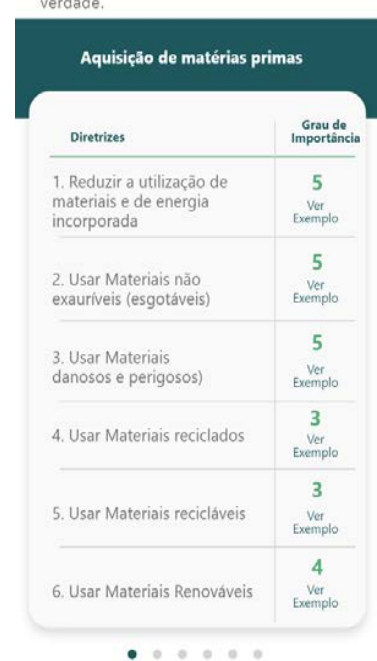

Avaliar um Projeto ou Produto

Figura 6: Tela Diretrizes. Fonte: da autora 
O app tem telas que são: Home, Início, Login, Menu, Biblioteca onde ficam os produtos avaliados, Análise, Feedback e Descrição das 60 diretrizes.

No software $x d$.adobe foram feitos os testes de usabilidade para acompanhar as passagens das interações e a sequência de ações. Durante o uso surgiu a necessidade de uma plataforma para a base de dados da biblioteca e a possibilidade de tornar a ferramenta uma adaptação para site. A partir das telas e dos resultados de interações passou-se ao desenvolvimento da programação por meio do software appinventor.

A solução para os cálculos da ferramenta foi resolvida em quatro passos: 1. Entrar com as informações e fazer o cálculo; 2. Guardar as informações no local; 3. Trocar informações de um app para outro e 4. Guardar as informações em uma base se dados em um servidor. Este procedimento está sendo realizado e testado.

A (Figura 7) mostra a avaliação de um produto, uma horta hidropônica que obteve 54 pontos.

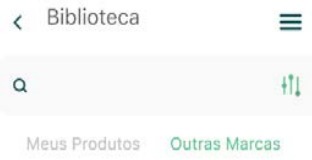

Resultado
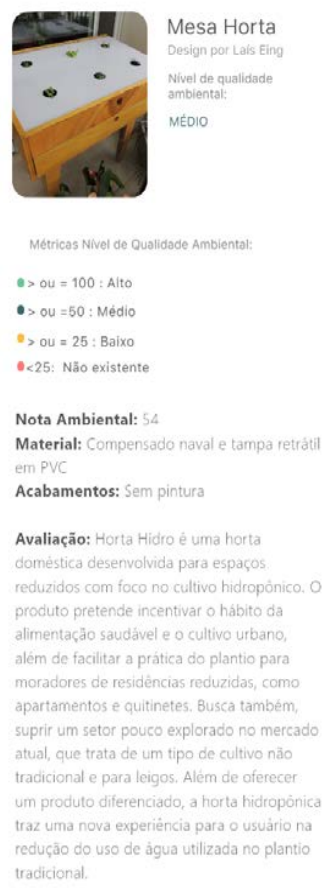

Figura 7: Tela Resultado. Fonte: da autora
A avalição de produtos como o mostrado na (Figura 7) indica as principais características ambientais e uma descrição da função do produto. $\mathrm{O}$ fato de ser um produto que atende medianamente a qualidade ambiental auxilia no processo de decisão de compra quando comparado com outro que não ofereça nenhum ponto positivo. $E$ durante o processo de design de um produto similar ou concorrente permite avaliar as características ambientais que ajudariam a estabelecer requisitos melhores para superar os concorrentes.

O app atualmente está na fase de programação e sendo desenvolvido também um site como mostra a (Figura 8).

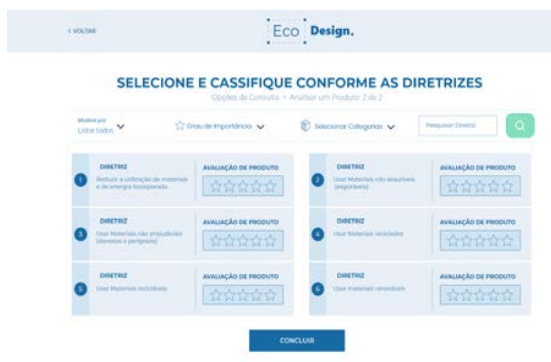

Figura 8: Site Eco Design. Fonte: da autora

Devido a que num site a tela do computador ou tablet permitem uma melhor visualização, a interface teve algumas alterações, por exemplo a nota dada por estrelas. E no app é uma lista flutuante. Assim que definidas as alterações de interação e navegação no site será aplicada a mesma identidade visual do app.

\section{CONCLUSÕES}

A pesquisa ofereceu bases conceituais e o resultado prático de uma ferramenta de diretrizes de projeto que pode ser utilizada para análise e auxilio no desenvolvimento de produtos com qualidade ambiental. A pesquisa atende a relevância de suprir por meio de uma ferramenta objetiva o crescimento de produtos ditos sustentáveis e a necessidade de mensurar, esclarecer e identificar a real qualidade do produto. A racionalidade de análise se dá pela mensuração em relação a dados científicos que estão por trás das 60 diretrizes de projeto. Estas diretrizes devem ser continuamente renovadas, ajustadas e incrementadas. A cada dia novas informações de testes em materiais, dados científicos dos impactos no meio ambiente por resíduos de não foram descartados de forma adequada ou por novos produtos que não conseguem ser desmontados e são descartados integralmente gerando o lixo eletrônico que tem crescido na última década.

A ferramenta pode auxiliar na compreensão da qualidade ambiental, no conhecimento de diretrizes que podem ser aplicadas no projeto considerando dados importantes ao longo do ciclo de vida e também para que o designer ou projetista seja crítico em relação aos produtos oferecidos no mercado e aos projetos que estão sendo desenvolvidos. $\mathrm{O}$ auxilio por meio das diretrizes durante o projeto permite que o designer pense e tome decisões acertadas. 
$\mathrm{Na}$ pesquisa buscou-se também rever o conceito de "verde" que é visto erroneamente como status, slogam ou adjetivo para vender mais e atrair o consumidor. O objetivo do artigo é promover para passar a ver e projetar o "verde" como um processo complexo de muitas dimensões em que as 60 diretrizes mostram ações que o projetista deveria considerar e fazer parte da sua prática projetual, uma profissão que precisa ser mais consciente e responsável.

Espera-se que o app esteja liberado para uso em 2021 após todos os testes e registro de propriedade intelectual.

Como trabalhos futuros, se percebe a necessidade de inserir a dimensão social que é uma linha de pesquisa que surge para ser incorporada a ferramenta. Como trabalho futuro tem se a necessidade de identificar diretrizes da dimensão social.

\section{REFERÊNCIAS}

Batista, W. B. (2007). Desenho Industrial e a ideologia da sustentabilidade. In: $4^{\circ}$ Congresso Internacional de Pesquisa em Design, Rio de Janeiro.

Cândido, Kariny. (2016). O coletivismo no design de produto aplicado à produção de cadeira baseada em encaixes. Projeto de Conclusão de Curso (PCC) do curso de design Universidade Federal de Santa Catarina. Florianópolis.
Deforge, Y. (1994). Por um Design Ideológico. In: Estudos em Design, volume II, número 1, Rio de Janeiro.

DESIGN COUNCIL. Duplo Diamante. Cody Wallis, 2005

Dougherty, Brian. (2011). Design gráfico sustentável. São Paulo: Rosari.

Garrett, Jesse James. (2010). The elements of user experience: the user-centered design for the web and beyond. 2 ed. Berkeley, CA: Pearson Education. 240 p.

McDonough, William; Braungart, Michael. (2005). Cradle to Cradle (De la cuna a la cuna) rediseñando la forma em que hacemos las cosas. Mc GrawHill. Madrid.

Papanek, V. (1977). Design para el mundo real: Ecología humana e cambio social. Madrid: Ediciones Blume.

Pazmino, Ana Veronica. (2017). Diretrizes de projeto para o meio ambiente como ferramenta de auxílio para análise e desenvolvimento de produtos com qualidade ambiental. ENSUS 2017 V Encontro de Sustentabilidade em Projeto. Florianópolis.

Thackara, J. (2008). Plano B: o design e as alternativas viáveis em um mundo complexo. São Paulo: Saraiva: Versar, 2008.

Schwaber, Ken; Sutherland, Jeff (2013). Guia to Scrum. Srum.org. 